OPEN ACCESS

International Journal of Management \& Entrepreneurship Research

P-ISSN: 2664-3588, E-ISSN:2664-3596

Volume 2, Issue 5, P.No. 314-331, October, 2020

Fair East Publishers

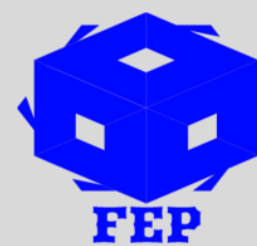

Journal Homepage: www.fepbl.com/index.php/ijmer

\title{
THE EFFECT OF ALCOHOLISM AMONG THE YOUTH OF ZONGO COMMUNITY OF WA IN THE UPPER WEST REGION OF GHANA
}

\author{
Justice Agyei Ampofo ${ }^{1}$ Antwi Abrefi Abigail ${ }^{2}$ \\ ${ }^{1}$ University for Development Studies, Tamale (Ghana) \\ ${ }^{2}$ University of Professional Studies, Accra (Ghana)
}

*Corresponding Author: Justice Agyei Ampofo
Corresponding Author Email: papajusty@gmail.com

Article Received: 10-09-20

Accepted: 27-09-20

Published: $15-10-20$

Licensing Details: Author retains the right of this article. The article is distributed under the terms of the Creative Commons Attribution-NonCommercial 4.0 License (http://www.creativecommons.org/licences/by-nc/4.0/) which permits non-commercial use, reproduction and distribution of the work without further permission provided the original work is attributed as specified on the Journal open access page.

\section{ABSTRACT}

There are many adverse consequences of drinking alcohol during youth age. However, there seems to be paucity of studies on alcohol usage among the youths in Ghana in general and Zongo Community youths in Wa Municipality in the Upper West Region of Ghana in particular. This research seeks to bridge this knowledge gap by determining the effects of alcoholism on the youth of Zongo Community in Wa of the Upper West Region of Ghana. The youth from Zongo Community were selected from the Wa Municipality. The sample consisted of 100 participants who were randomly sampled. The data gathering tool was a 41 item questionnaire containing both open and close-ended questions. The data was analysis in percentages and findings were presented in the form of tables, pie charts and bar charts. The study revealed a high rate of alcohol consumption among youths of Wa Zongo community. The study also revealed that males consume more alcohol as compared to females. It was also found that peer influence, family history of alcohol use and stress are the major causes of alcohol use among youth of Zongo Community in the Wa Municipality. The study recommends for 'Alcohol Anonymous' groups to be formed in Wa Zongo Community as well as policies to control the sale and use of alcohol among youth of Zongo Community in the Wa Municipality of Ghana.

Keywords: Alcoholism, Youth, Zongo Community, Wa, Upper West Region, Ghana 


\section{INTRODUCTION}

Alcohol is one of the most widely used substances in the world (Zieve, 2011). Alcohol, also known as ethyl alcohol or ethanol is an intoxicating ingredient found in beer, wine and liquor. It is a central nervous system depressant that is rapidly absorbed from the stomach and small intestine into the blood stream. Alcohol is found in many kinds of beverages (Tse, 2011). In Ghana, alcohol is found in palm wine, locally distilled gin or 'akpeteshie', 'pito', and 'atemuda'. Other foreign forms of alcohol include vodka, martini, dry gin and champagne. A research conducted by Ofori Atta in 2006 reported that 40-50\% of people who consume alcohol in Ghana consume locally distilled gin also known as 'akpeteshie', $0.25-0.35 \%$ consumed local beer such as 'pito', 'brukutu', 5-7 \% took industrially produced gin and 3.5\% took palm wine. According to a WHO report in 2003, beer is the most consumed alcoholic beverage in Ghana.

Alcohol usage among the youth in Ghana is common nowadays in Ghana. Alcohol use comprises of alcoholism and alcohol abuse. Alcoholism and alcohol abuse are two different forms of alcohol use disorders (Hingson et al, 2002; Griffiths, 2006). Alcoholism is when one has signs of physical addiction to alcohol. Such a person, though he/she may have problems with physical health, mental health, social, family or job responsibilities, will continue to drink. It, thus, becomes a chronic disease in which one has a strong craving and becomes dependent on alcohol. Shin (2009) said that when one suffers alcoholism, one loses control over their drinking (The Community Anti-Drug Coalitions of America, 2012).

According to the Institute of Alcoholism and Alcohol Abuse report in 2009, the intensity of the effects of alcoholism on the drinker's body varies with age. The older a person gets, the weaker his body gets and the more prone he/she is to the effects of alcohol. Older people have slower reaction times, problems with hearing and seeing and a lower tolerance to alcohol's effects (Hung et al, 2003). These put older people at a higher risk for falls, car crashes and other types of injuries that may result from drinking. Youth are more likely to suffer from the side effects of alcohol use which include appetite changes, weight loss, eczema, headaches and sleep disturbance (Newburg, Gilvary, McArdle, Stewart, Walker et al., 2009).

Alcohol consumption among the youth is very high (The National Collegiate Athletic Association, 2009). Castella (2010) wrote that out of the proportion of people who currently use alcohol in the USA, most fall between the ages of 18 and 21. They also said that about $90 \%$ of the alcohol consumed in the United States is consumed by the youth under 21 years. Johnson, Bewick, O'Connor \& Shickle (2011) also said that among young adults, college students have the highest prevalence of high-risk drinking. From observation, most of the youth in Ghana especially at Zongo Community in the Upper West Region (Wa) fall within the ages of 18 and 26 years. In these Zongo Community, activities that promote alcohol use among the youth are embedded in advertisement of alcohol in social media such at television stations, radio stations among others. These activities include promotion of alcohol beverages, drinkups and beach parties.

It is important to note that most of these youth who take the alcoholic drinks do it for a reason, the most noted one being social pressure or influence. Over the past decade, alcohol use has become a major health concern among people around the world. Alcohol use among the youth in areas like Zongo Community in the Wa Municipality of the Upper West Region of Ghana has become common because the youth are exposed to intake of alcohol every day, sale of 
alcoholic beverages in and around the areas of residence, peer influence from colleagues who consume alcohol, to signify their emerging adulthood, and the urge to be seen as being "in tune with times." This coupled with the fact most of the youth in Wa Zongo Community are considered adults and as such, are left to make their own decisions and the absence of parental supervision makes it easier for the youth to engage in alcohol use. It is for this reason that the researcher deemed it necessary to research into the effects of alcoholism on the youth of Wa Zongo Community in the Upper West Region of Ghana.

\section{REVIEW OF RELATED LITERATURE}

\section{Causes of Alcohol Use among the Youth}

The causes of alcohol use refer to the reasons or the factors that may lead someone to drink. Common factors identified by researchers include community environment and customs, peer influences, family history of alcohol use among others.

\section{a. Environment and Customs}

A variety of researches have indicated that the nature of environments, where every child is considered as an adult coupled with the independence of each person, the activities organized on some areas with communities and the exposure of the youth to various activities put the youth at risk of alcohol use. Several researches have also indicated that youths are often undergoing role transitions such as moving away from the family for the first time, residing with other students, and experiencing reduced adult supervision which all put the student at risk of engaging in alcohol use (Latendresse, 2008). Zongo youth also frequently reside in a different physical and social environment and encounter new social and institutional factors, such as parties, and sitting in groups taking pito and other beverages which may foster heavy alcohol use. Customs that promote youth drinking are embedded in some communities.

\section{b. Peer Influence}

Peer influence refers to the pressure from ones friends, to behave in a manner similar to or acceptable to them. Peer group is a key agent of socialization. As children grow up and become adolescents, they look to their peers for self-definition, socialization, friendship and support.

A number of studies have also indicated that peer influence is perhaps the highest predictor of alcohol use among the youth (Marie, 2001). The Center for Disease Control (CDC) (2010) said that youth are influenced more by peers than their families when it comes to alcohol use. Laibson (2001) also wrote that the youth in our communities have a greater motivation to drink for peer acceptance. Peers could affect a persons' preferences. For example, seeing friends consume an addictive substance could act as a cue and stimulate the persons' desire for that substance.

A cross-sectional study conducted in 2009 by Chikere \& Mayowa to determine the prevalence and perceived health effects of alcohol use among the youth in Owerri in Nigeria found out that the percentage that engaged in alcohol use is $46.8 \%$ and they were introduced to it by a friend. A random sample of 482 male students from Federal University of Technology, Imo State University, Federal Polytechnic of Nekede and Alvan Ikoku Federal College of Education with an average age of 24 years was used for the study. Out of the $78.4 \%$ of students who said they drank alcohol, $83 \%$ of them started drinking in college and $1.6 \%$ stated that they used alcohol because their friends did too. 


\section{c. Family History and Parental Behaviour}

The family is the main environment where children are socialised and learn individual behaviour. The type of family a person belongs to greatly affects his/her lifestyle and the choices he/she makes in life. If a person belongs to a family which has a history of alcohol use, it is more likely for the person to also indulge in alcohol use. The lifestyles of one's parents also greatly influence him/her. This is because parents are mostly responsible for imbibing of morals into their children. Newman (2002) wrote that, there is a direct relationship between parental alcohol use and their children's use of alcohol and Moore (2007) said that the drinking habits of family members has an impact on students' drinking behaviour such that when a family member drinks, youth in the family are also more likely to drink.

In an attempt to establish the relationship between parental alcohol consumption and consumption of alcohol by the youth, Johnston et al (2006) analysed data collected by the Harvard School of Public Health for the College Alcohol Study conducted in 2001. This study was conducted to determine the effects of parental attitude and alcohol use on youth drinking. The study used randomly selected students from 119 colleges and universities. In all, 10,904 students were surveyed through mailed questionnaires. Benzmiller's analysis revealed that there is a significant positive correlation between parental attitude towards alcohol use and children (youth) drinking. The results indicated that parental attitude towards alcohol use contributes $7.5 \%$ to their offspring's drinking, if all other factors such as gender, race, level of study in school, school alcohol policy and residential status are eliminated.

\section{The Extent of Alcohol Use among the Youth}

According to National Survey on Drug Use and Health report in 2006, the extent of alcohol use refers to the rate of alcohol use among youth, how often they consume alcoholic beverages and the quantity of alcohol they usually consume at a sitting, where at a sitting means 'within a short period.' The extent of alcohol use among the youth has remained consistently high over the years, with several researches indicating high rates of consumption. Wechsler, Lee, Kuo, \& Lee (2000) wrote that the majority of today's youth drink alcohol.

Powell et al (2002) also said that youth age represent the prime drinking years for most alcohol users, that is to say that for most alcohol users, the time that they drank most was when they were in their youthful ages. Johnston (2002) also reported that students aged between 18 and 22 drink more alcohol. The National Survey on Drug Use and Health (NSDUH) is an annual survey which is conducted to determine the prevalence, symptoms and consequences of alcohol use amongst young adults between the ages of 18 and 22 in the USA. The survey uses a representative national sample of approximately 70,000 people who are interviewed using computer-assisted interviewing methods.

More studies have confirmed the high prevalence of alcohol use among youth. Atwoli, Mungla, Ndun'gu, Kiende, Ogot et al., (2011) also did a cross-sectional survey among students in four tertiary institution found in the Eldoret municipality, Kenya on the topic, "prevalence of substance use, including alcohol use among the youth." Out of the 500 students sampled randomly in these schools, 478 responded to questions on alcohol use. 248 respondents out of this number, representing $51.9 \%$ of the sample use alcohol. Out of these alcohol users, $97.6 \%$ responded that they had had an alcoholic drink one week prior to the study. Results also showed that these students had an average of 3 drinks per day with $50.4 \%$ 
admitting to having taken 5 or more drinks per day on one or two days in the preceding month, while $9.2 \%$ had done so on 3 or more days. The research concluded that the prevalence rate of use of alcohol was very high among the youth raising the necessity for the implementation of targeted interventions programmes to reduce the problem. Researchers concluded that the rate of use of alcohol was high and that the surveillance needed to be continued to enable the nation follow the trends of alcohol and substance use and make policies to control it.

\section{Effects of Alcohol Use on the Youth}

The effects of alcohol use refer to the probable or actual outcomes associated with the use of alcohol. These effects may be positive or negative (Taner, 2005). Alcohol use has been seen to have various effects on the youth who consume it and the people around them. The consumption of alcohol can be expected to have negative effects on the youth both directly through its potential impact on cognitive ability or indirectly through its impact on their health condition (Powell, Williams and Wechsler, 2002). It has been suggested that binge drinking is a serious public health hazard and the primary cause of preventable morbidity and mortality for more than 6 million youth in the United States (Marczinski, Combs, \& Fillmore, 2007). More than 150,000 youth in school develop an alcohol-related health problem and between $1.2 \%$ and $1.5 \%$ of students indicate that they tried to commit suicide within the past year due to drinking or drug use (Hingson, et al., 2002).

Atwoli et al (2011) also reported on the study of alcohol and drug use in the four Kenyan universities that, possible problems attributed to alcohol use include quarrels or arguments, scuffles or fights, accidents or injury, loss of money or other valuable items, damage to objects or clothing and problems in relationships between students and their parents. About $82.7 \%$ of respondents who used alcohol said they had gotten into arguments or quarrels while drunk, $68.1 \%$ had fought with others and $68 \%$ had had problems with their friends and their parents because of their use of alcohol.

The consequences of alcohol related youth violence can be devastating. Krug, Dahlberg, Mercy et al., (2002) reported that harmful and hazardous alcohol use is a risk factor for being victimized and perpetrating youth violence. Youth violence takes many forms including bullying, gang violence, sexual aggression and assaults occurring on the streets, in bars, nightclubs and even college campuses. These victims and perpetrators alike are young people. Alcohol use directly affects cognitive and physical function. Benzmiller (2008) also wrote that hazardous alcohol use can reduce self-control and the ability to process incoming information and can reduce emotional stability and impulsivity, to make drinkers more likely to resort to violence and confrontation.

\section{METHODOLOGY}

\section{Research Design}

The researchers used descriptive survey through which views and opinions were sampled from the youth of Zongo Community in Wa Municipal. Ampofo, Amoah and Peprah (2020) view descriptive survey as a design that portrays accurately the characteristic of particular individual situations or groups. In other words, the descriptive survey is a research method that is non-experimental and deals with the relating among non-manipulated variable. A descriptive survey also provides a quantitative or numeric description of trends, attitudes, or opinions of a population by studying a sample of that population. It includes cross-sectional 
and longitudinal studies using questionnaire or structured interviews for data collection, with the intent of generalising from a sample to a population (Creswell, 2013; Ampofo, 2020). Specifically, the study seeks to determine the effects of alcoholism on the youth of Zongo Community in Wa of the Upper West Region of Ghana.

\section{Research Setting}

The study was undertaken at the Zongo Community in the Upper West Region of Ghana It is located within Wa township. The Wa Zongo Community has about 29,754 youths.

\section{Target Population}

Population refers to all individuals who have in common, certain characteristics that are of interest to the researcher. The target population of this study was all youth in the Zongo community of Wa township, both males and females.

\section{Sample Size and Sampling Technique}

According to Ampofo (2020), sampling refers to 'the search for typicality.' The probability sampling technique was used, of which a simple random sampling method was adopted in the selection of participants. A probability sampling refers to a situation where each individual in the population has a chance of being selected in the sample. Simple random sampling is when subsets have an equal probability of selection, and the population is not subdivided. This method was used because the researchers wanted to be able to generalize the findings of the study as being representative of the general youth population. Since it was going to be difficult to collect information from all the youth in the Zongo community of Wa township, a sample size, which is a select fraction to represent the whole population, was used. 100 youth were therefore randomly selected to participate in the study. The sample comprised of 60 males and 40 females.

\section{Data Gathering Tool}

A structured questionnaire containing 30 items, including both open-ended and close-ended questions were used as the data gathering tool. Close-ended questions were used because they offered a limited number of response alternatives and therefore gives precision to responses. The open-ended questions were also used because it gives the respondent the freedom to answer anyway they liked. It yields a valuable insight into what people think and how they view the world and things that occurs in it. The questionnaire was divided into four sections; section A collected information on participants' demographic data, which was used to determine the category of youths who used alcohol more. The rest of the sections asked questions to collect information on alcohol use among students. Section B asked questions on the extent of use of alcohol, collecting data on how often respondents used alcohol, types of alcoholic beverages used and the number of bottles or glasses they took at a sitting. Section C also asked questions on the causes of alcohol use among participants. The last section, D asked questions on the knowledge of and effects of alcohol use on youth health. This was administered to the selected respondents to fill out.

\section{Data Collection Procedure}

Data collection was done by the researchers. Permission was sort from the chief of Zongo Community in Wa township before the study was conducted. Personal presentation of the questionnaires to respondents was done so that the researchers could clarify any questions as well as explain the purpose of the study. Informed consent was sought and a step by step explanation of how the questionnaire will be answered was given to the respondents. 


\section{Data Analysis}

Analysis of data provided facts and figures that enabled interpretation of the results and reaching conclusions from the findings of the study. All items of the questionnaires were coded. Items in the form of Likert scale were rated between $4-1$, with 4 being the highest and 1 being the lowest. Questionnaires were edited to ensure that clear, legible, relevant, and appropriate responses had been provided. The coded items and their corresponding frequencies were fed into the computer using the SPSS software programme. Data were analyzed using simple percentages and frequencies, charts and tables.

\section{Validity and Reliability}

Validity of a research is attained when a research tool measures what it is intended to measure, based on the purpose of the study (Ampofo, 2017; Ampofo, 2020). In order to achieve this, the researchers ensured that all questions included in the questionnaire were in congruence with the purpose of the study.

Reliability of a research also refers to the consistency of the research, such that, if the same population and the same method of study are used together with a similar purpose, results will be similar or the same (Ampofo, 2017: Ampofo, 2020). In order to ensure this, the researchers made sure that, results from the collected data were a true reflection of the population and that no personal or biased judgements were included in the study.

Pre-testing was done prior to data collection, in that 10 students who were not part of the study were also randomly chosen to answer the questionnaire and questions that could not be understood or weren't clear enough were rephrased to clarify it.

\section{DISCUSSION OF RESULTS}

\section{Demographic Information}

The demographic information sought to find out the age brackets within which the respondents fall, their gender and religion.

\section{Age of Respondents}

Out of the total number of respondents, $23 \%$ were aged between 15-19 years, $60 \%$ were within the ages of 20-24 years, $15 \%$ were aged between 25-29 years while 2\% were aged above 29 years. This is displayed in table 4.1 .

\begin{tabular}{|c|c|c|}
\hline \multicolumn{3}{|l|}{ Table 1} \\
\hline AGE GR & PFRI & YPERCENTAGE (\%) \\
\hline $15-19$ & 23 & 23 \\
\hline $20-24$ & 60 & 60 \\
\hline $25-29$ & 15 & 15 \\
\hline Above 29 & 2 & 2 \\
\hline Total & 100 & 100 \\
\hline
\end{tabular}

\section{Sex of Respondents}

Majority of the students sampled (60\%) were males while the females formed $40 \%$ of the total number. This is illustrated in figure 1. 


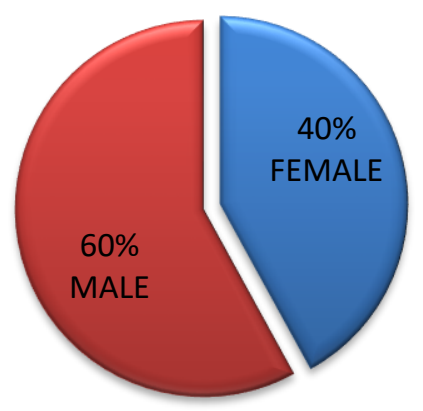

Figure 1: Sex of Respondents Source: Field Survey, (2017)

\section{Causes of Alcohol Use}

This section sought to identify the various reasons why respondents consume/consumed alcohol. Out of the number of respondents who have ever used alcohol, 17 respondents forming $22.08 \%$ said it was to help them cope with stress, 18 respondents forming $23.38 \%$ said because their friends use alcohol, 6 respondents forming $7.79 \%$ said it was because their relatives use alcohol, 1 respondents forming $1.30 \%$ said it was because alcohol use is in the " in thing”, 12 respondents forming $15.58 \%$ said it was because they are grownups and 23 forming $29.87 \%$ said it was because alcohol gave them pleasure.

Table 2

Reasons for Using Alcohol

\begin{tabular}{lll}
\hline Reasons for consuming alcohol & FREQUENCY & PERCENTAGE (\%) \\
\hline To help cope with stress & 17 & 22.08 \\
\hline Because friends use alcohol & 18 & 23.38 \\
\hline Because relatives use alcohol & 6 & 7.79 \\
\hline Because alcohol use is in the "in thing" & 1 & 1.30 \\
\hline Because they are grown ups & 12 & 15.58 \\
\hline Because alcohol gives pleasure & 23 & 29.87 \\
\hline Total & $\mathbf{7 7}$ & $\mathbf{1 0 0}$ \\
\hline
\end{tabular}

Source: Field Survey, (2017)

\section{Knowledge of specific people who use alcohol}

This question wanted to find out the particular people that respondents knew they take alcohol and if they were influenced to drink by these people. 12 respondents said parents, 11 respondents said guardians, 7 respondents said siblings, 32 respondents said friends, 9 respondents said role models and 29 respondents said others/neighbors. This is shown in Figure 2 below. We also wanted to find out if any of these people ever used alcohol in the presence of the respondents. 75 respondents answered 'yes' while 25 respondents answered 'no'. Out of the $75,59 \%$ responded that they believed they were influenced to drink by these people while $41 \%$ answered in the negative hence a 'no' answer. 


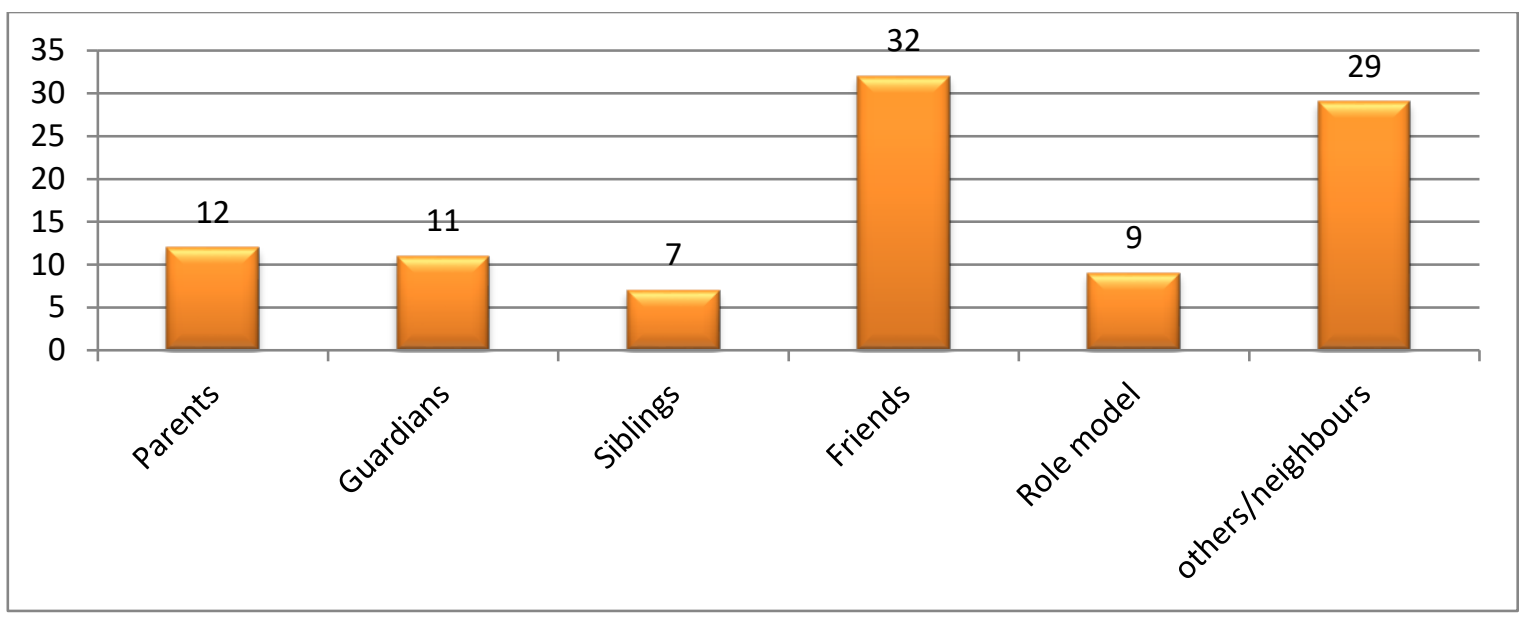

Figure 2: Knowledge of specific people who use alcohol Source: Field Survey, (2017)

\section{Extent of f Alcohol Use}

This section depicts the rate of alcohol use among the youth of Zongo community, the frequency of use of alcoholic beverages and the quantity of alcohol, in terms of glasses, they usually consume at a sitting. This section also includes history of alcohol use among the youth, the various alcoholic beverages used by them, sources of alcoholic beverages, frequency at which the youth get drunk and where the youth consume alcohol.

\section{History of Alcohol Use}

For the history of alcohol use among the youth, 77 respondent forming $77 \%$ of the respondents claim to have used alcohol in their life time with only $23 \%$ claiming not to have used alcohol.

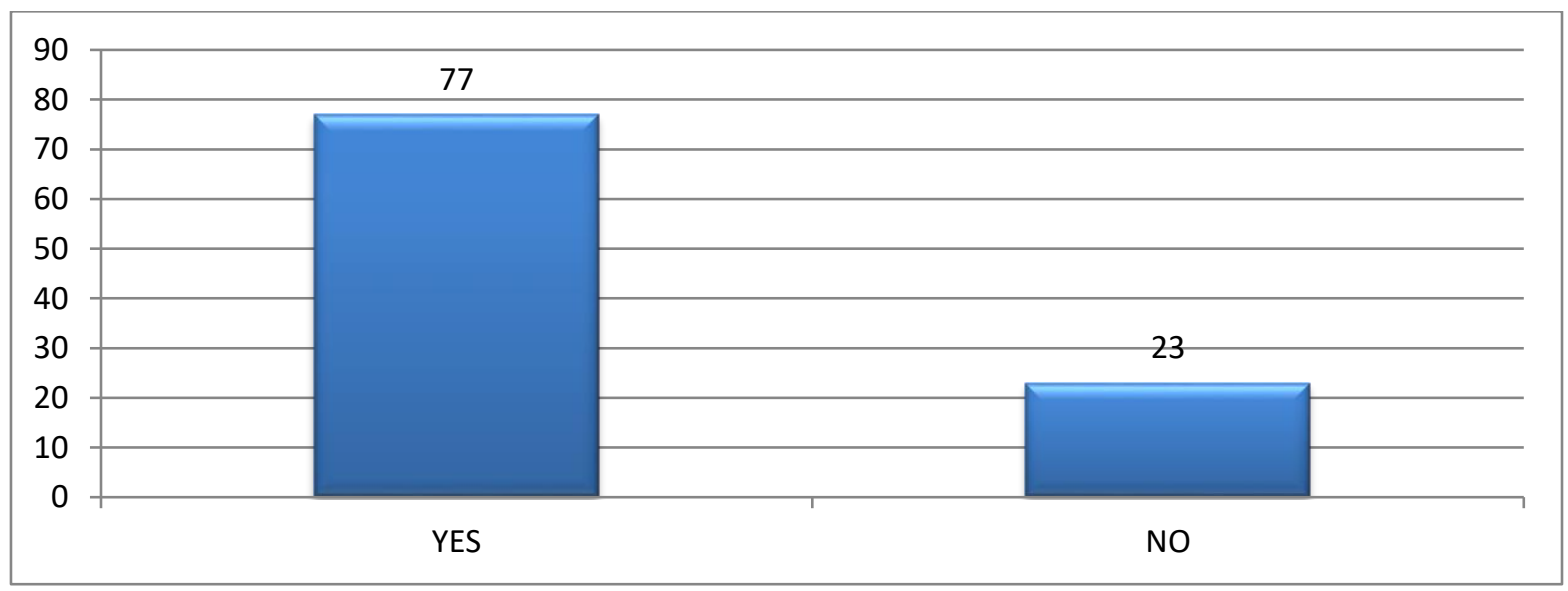

Figure 3: History of alcohol use

Source: Field Survey, (2017)

\section{Current rate of use of alcohol}

Sixty-four (64) respondents forming $64 \%$ of the total sample claimed that they currently use alcohol. 13 respondents, representing $16.9 \%$ of the total respondents with a history of alcohol use claimed that they had quit using alcohol.

\section{Alcoholic Beverages used by Respondents}


Responses from the data collected show that the youth use different brands of alcohol. The various types of alcohol the youth have ever used before are shown in figure 4 below. $36 \%$ of the respondents have ever used beer, $14 \%$ have ever used wine, $13 \%$ have ever used gin, $10 \%$ have ever used pito and $4 \%$ have used other brands of alcohol not listed in the above. The remaining $23 \%$ claim that they do not use alcohol.
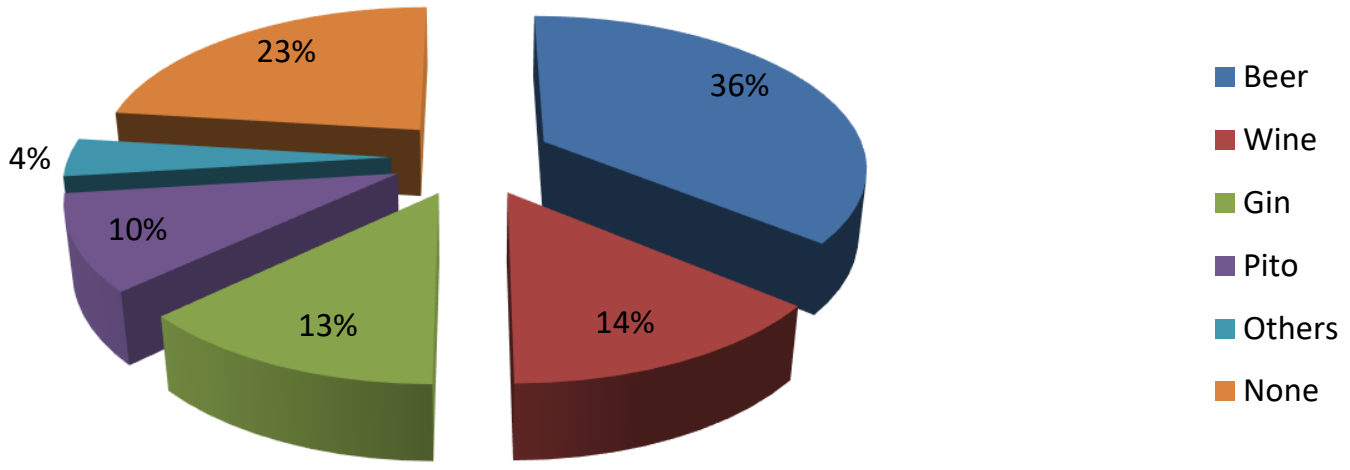

Figure 4: Various Alcoholic beverages ever used by respondent Source: Field Survey, (2017)

\section{Quantity of Alcohol Used}

This depicts the quantity of alcohol, number of glasses, youth consume per sitting. Out of the number of respondents with history of alcohol intake, 20 respondents forming $25.97 \%$ claim to take only a glass of alcoholic drink at a sitting, 31 respondents forming $40.26 \%$ claim to use 2 glasses, 15 respondent forming 19.48\% said 3 glasses, 9 respondents forming $11.69 \%$ said 4 glasses and 2 respondents forming $2.60 \%$ said 5 or more bottles. This is shown in Table 3.

Table 3

\begin{tabular}{cll} 
Quantity of Alcohol Used & \\
\hline \multicolumn{1}{l}{ Number of glasses } & FREQUENCY & PERCENTAGE (\%) \\
\hline 1 & 20 & 25.97 \\
2 & 31 & 40.26 \\
3 & 15 & 19.48 \\
4 & 9 & 11.69 \\
5 or more & 2 & 2.60 \\
Total & $\mathbf{7 7}$ & $\mathbf{1 0 0}$ \\
\hline
\end{tabular}

Source: Field Survey, (2017)

\section{Frequency of Alcohol Use}

This sought to find the number of times respondents consume alcohol in a week. In all 36 respondents said they do not use alcohol hence a 'none' answer, 11 respondents said once a week, 27 respondents said twice a week, 12 respondents said 3 times a week, 8 respondents also said about 4 times and 6 respondents claim 5 or more times. This is illustrated in the figure below. 


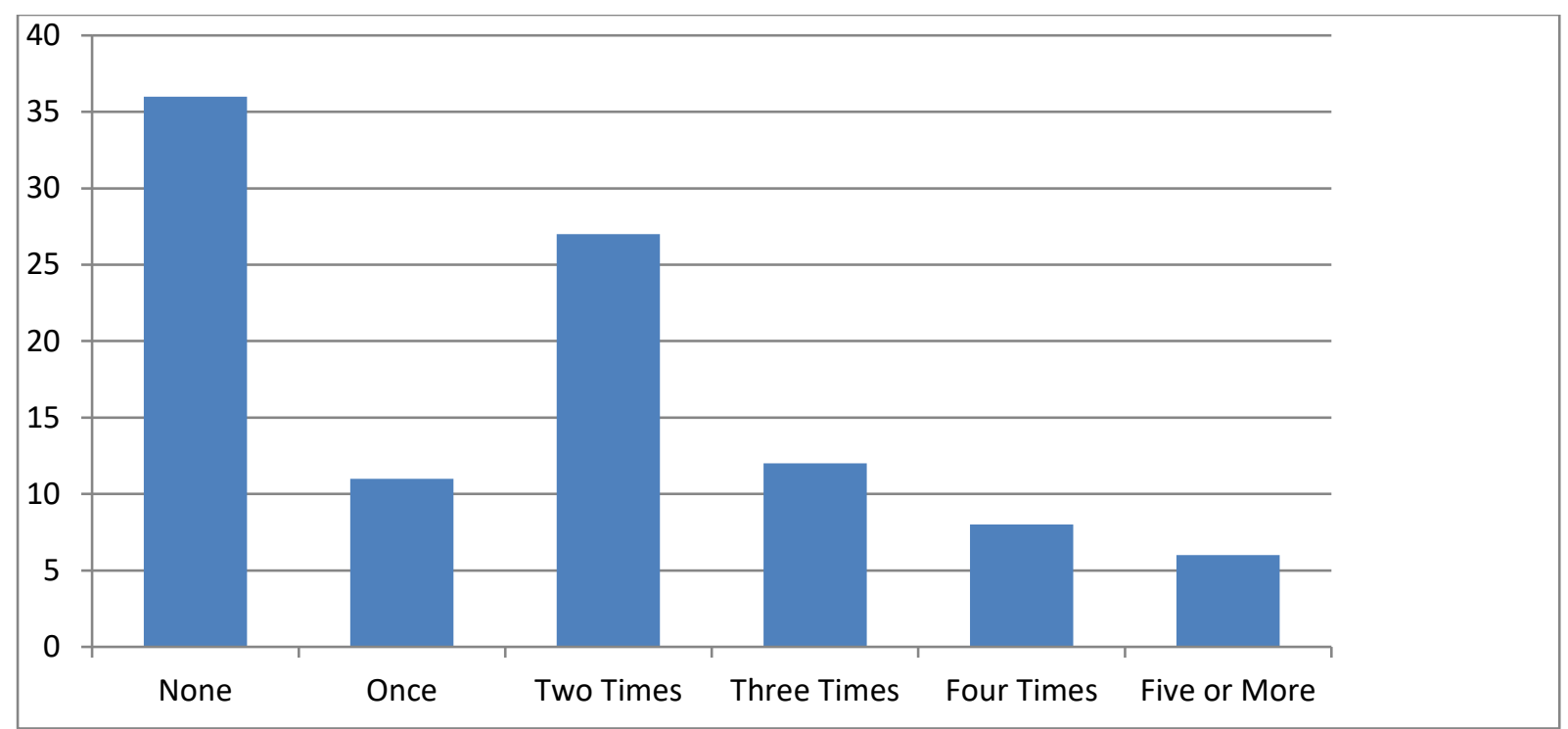

Figure 5: Frequency of alcohol use Source: Field Survey, (2017)

\section{Frequency of Drunkenness among the Youth}

For the respondents who use alcohol, some got drunk at certain times and others never got drunk. Out of the number of respondents who have ever used alcohol, 56 respondents forming $72.27 \%$ claim they have ever gotten drunk while 21 respondents forming $27.27 \%$ claimed they have never gotten drunk. For the number of times respondents have gotten drunk in a week, 17 respondents claim they usually got drunk once, 24 respondents said 2 times, 15 respondents claim 3 times none said 4 or more times.

\section{Sources of Alcohol}

Here, we wanted to find out where the respondents got their alcohol from school. Majority of the respondents, 40, forming 52\% said they got alcohol from bars outside their homes, 18 respondents forming $23 \%$ said they got their supply of alcohol from bars, 8 respondents forming 10\% said from home, 9 respondents forming 12\% said club house and 2 respondents forming $3 \%$ said others. This is displayed in Figure 5.

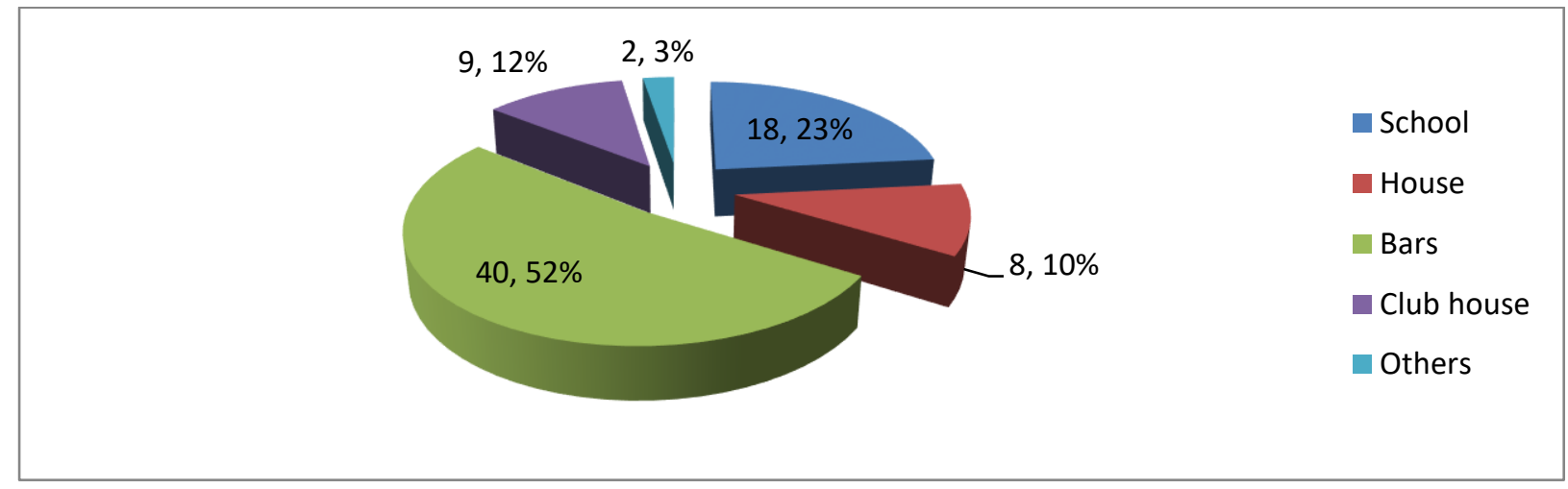

Figure 5: Sources of alcohol for respondents who take alcohol

Source: Field Survey, (2017)

\section{Place of Consumption}

We wanted to find out where the respondents normally consume their alcohol. In all, 8 respondents forming $10.39 \%$ said they consumed alcohol in their rooms, 34 respondents 
forming $44.16 \%$ said at a bar, 6 respondents forming $7.79 \%$ said at an event, 27 respondents forming $35.06 \%$ said at a bar outside their area and 2 respondents forming $2.60 \%$ said in a car. This is shown in Table 4.

Table 4

Place of Consumption

\begin{tabular}{lll}
\hline Place of consumption & FREQUENCY & PERCENTAGE (\%) \\
\hline In the room & 8 & 10.39 \\
At a bar/restaurant & 34 & 44.16 \\
At a campus event & 6 & 7.79 \\
At a bar outside area & 27 & 35.06 \\
In a car & 2 & 2.60 \\
Total & $\mathbf{7 7}$ & $\mathbf{1 0 0}$ \\
\hline \multicolumn{2}{c}{ Source: Field Survey, (2017) }
\end{tabular}

\section{Effects of Alcohol Use}

In this section, we wanted to find out the various consequences resulting from the use of alcohol on the youth of Zongo community in the Wa Township and the people around them.

\section{Respondents who exhibited behaviour when drunk}

Here, we wanted to find out if respondents exhibited any forms of behavior when they got drunk which they wouldn't otherwise have done. Majority $(72.72 \%)$ of the respondents had gotten drunk before. In all, 51 respondents depicting 66\% said 'yes' to mean they exhibited certain behaviour when drunk with 26 respondents giving a 'no' answer. Majority (41\%) of those who exhibited bizarre behaviour while drunk said that they insulted people or got into petty quarrels when they were drunk.

\section{Respondents who sustained injuries when drunk}

This question sought to find out if respondents had ever sustained any form of injury while they were drunk and in response, 38 respondents said they had been injured as a result of alcohol use before while 39 said they had never been injured as a result of alcohol use. 21 of these representing 55.3\% said that they had had bruises from falls as a result of drinking.

\section{Awareness of health effects of alcohol use}

Here, we wanted to find out if respondents knew of any effects of alcohol use. 32 respondents forming $32 \%$ claim to be aware of health effects associated with the use of alcohol while 68 respondents forming $68 \%$ claim not to be aware of any alcohol related health effects.

\section{Knowledge on specific health related problems}

Here, we wanted to ascertain the knowledge respondents have on the specific health problems related to alcohol use. As shown in Table 5 below, 6 respondents (18.75\%) chose hypertension, 4 respondents $(12.5 \%)$ chose low birth weight, 3 respondents $(9.38 \%)$ chose stroke and sudden death, 1 respondent $(3.13 \%)$ chose HIV/STI, 13 respondents $(40.63 \%)$ chose liver disease and 5 respondents $(15.63 \%)$ chose heart diseases.

Table 5

\section{Knowledge on Specific Health related Problems}

\begin{tabular}{lll}
\hline Responses on specific health problems & FREQUENCY & PERCENTAGE (\%) \\
\hline Hypertension & 6 & 18.75 \\
Low birth weight & 4 & 12.5 \\
Stroke and sudden death & 3 & 9.38 \\
HIV/STI & 1 & 3.13 \\
Liver diseases & 13 & 40.63 \\
\hline
\end{tabular}




\begin{tabular}{lll}
\hline Heart diseases & 5 & 15.63 \\
Total & $\mathbf{3 2}$ & $\mathbf{1 0 0}$ \\
\hline \multicolumn{3}{c}{} \\
\hline
\end{tabular}

\section{Other Effects associated with Alcohol Use}

This question sought to find out respondents' views on other probable effects related to alcohol consumption. With the aid of a Likert scale, respondents were asked to express their views in this form: S.D (1) represents the views for strongly disagree, D (2) represents the views for disagree, $\mathbf{U}$ (3) represents the views of those uncertain, A (2) represents the views of those who agree and S.A represents those who strongly agree. The findings are presented in table 6 below

Table 6

Effects of Alcohol Use

\begin{tabular}{lllllll}
\hline Effects & S .D(1) & D (2) & U (3) & A (4) & S.A (5) & Total (\%) \\
\hline Gives a good feeling & $13(13 \%)$ & $17(17 \%)$ & $12(12 \%)$ & $16(16 \%)$ & $42(42 \%)$ & $100(100 \%)$ \\
Enhances sex & $20(20 \%)$ & $9(9 \%)$ & $10(10 \%)$ & $23(23 \%)$ & $38(38 \%)$ & $100(100 \%)$ \\
Completes social gathering & $49(49 \%)$ & $21(21 \%)$ & $0(0 \%)$ & $0(0 \%)$ & $30(30 \%)$ & $100(100 \%)$ \\
Leads to strained relations & $46(46 \%)$ & $17(17 \%)$ & $12(12 \%)$ & $10(10 \%)$ & $15(15 \%)$ & $100(100 \%)$ \\
Causes feeling of remorse & $10(10 \%)$ & $14(14 \%)$ & $4(4 \%)$ & $16(16 \%)$ & $2(2.5 \%)$ & $100(100 \%)$ \\
Leads to pretty quarrels & $0(0 \%)$ & $1(1 \%)$ & $9(9 \%)$ & $12(12)$ & $78(78 \%)$ & $100(100 \%)$ \\
Leads to vandalism & $12(12 \%)$ & $10(10 \%)$ & $8(8 \%)$ & $2(2 \%)$ & $68(68 \%)$ & $100(100 \%)$ \\
Causes absenteeism & $0(0 \%)$ & $0(0 \%)$ & $3(3 \%)$ & $21(21 \%)$ & $76(76)$ & $100(100 \%)$ \\
Causes low academic work & $6(6 \%)$ & $17(17 \%)$ & $10(10 \%)$ & $4(4 \%)$ & $63(63 \%)$ & $100(100 \%)$ \\
\hline \multicolumn{7}{c}{ Source: Field Survey, (2017) } \\
\hline
\end{tabular}

\section{DISCUSSION AND SUMMARY OF MAJOR FINDINGS}

\section{Causes of Alcohol Use}

This aspect of the study investigated the reasons or the factors that leads Wa Zongo community youth to use alcohol. The study revealed that majority of the respondents (29.9\%) used alcohol because it gave them pleasure. This tally with the findings from the study by Chikere and Mayowa in 2009 among the 482 male undergraduate students in universities in Owerri, Nigeria, where only $24.4 \%$ of the respondents said they used alcohol because it made them feel 'high'. This indicates that most of the youth in our study use alcohol because they find pleasure in drinking.

Most $(23.4 \%)$ of the respondents also stated that the reason why they used alcohol was because their friends used it too. This also agrees with the findings by Tse (2011) that the youth are more likely to be influenced by their peers to use alcohol. However, our findings differ from the findings from Chikere et al (2009)'s study because in their study, only $1.6 \%$ of the responded that they used it because their friends used it too. This indicates that peer influence is a contributing factor to the high rate of alcohol use among students in our study.

A significant number of respondents $(22.08 \%)$ also responded that they used alcohol because it helped them to cope with stress. This also agrees with the 2010 Core Institute study among students in Illinois on alcohol and other drugs use in which about $43.1 \%$ of their respondents responded that they used alcohol because it helped them to relieve stress. This indicates that even though peer influence and drinking for pleasure are major causes of alcohol use, a significant number of respondents also use alcohol in order to cope with stress. 


\section{Extent of alcohol use among the youth of Zongo Community in Wa}

This sought to identify the extent of alcohol use among the youth in terms of the rate of alcohol use among them, how often they consume alcohol and the amount of alcohol they consume per sitting. Majority $(77 \%)$ of the respondents have engaged in alcohol use at least once in their lifetime and 64\% currently use. This indicates that there is a high prevalence of alcohol use among the youth in Zongo community in Wa This is in agreement with the findings of Wechsler et al (2000) that majority of today's youth drink. It also tallies with the results of the ASSAD survey that there is a high prevalence of alcohol use among the youth in developing countries.

Findings from our study also showed that majority (36\%) of the students preferred beer to the other types of alcohol. This indicates that beer is the preferred alcoholic beverage for most youth who consume alcohol followed by wine and gin. This is in line with the WHO report in 2003 that beer is the most used alcoholic beverage in Ghana. In terms of quantity of alcohol consumed by the youth, majority (40\%) of the respondents took in 2 glasses at a sitting. Only $2.60 \%$ of the respondents used 5 or more glasses at a sitting. This indicates that, majority of the youth in Zongo community in the Upper West Region of Ghana who use alcohol do not engage in binge drinking

\section{Effects of Alcohol Use}

Our study found out that, many $(66 \%)$ of the youth who got drunk exhibited certain behavior that they would not have if they were not drunk. About $78 \%$ of the respondents agreed that alcohol use led to petty quarrels and $68 \%$ agreed that use of alcohol could lead to vandalism and destruction of school properties.

This confirms the study by Atwoli et al(2011) where $86 \%$ of the 248 respondents selected from the four Kenyan universities responded that they had acted in ways they wouldn't have if they were not drunk. There were also about $49 \%$ of the respondents who also responded that they had been injured whilst drunk. This shows that majority of the youth who use alcohol exhibit certain behavior while they are drunk and they regretted these behaviour after they became sober. Also, a significant number of the youth sustained injuries because they were drunk.

In terms of awareness of the health effects of using alcohol, $68 \%$ of the respondents said that they were not aware of any health effects associated with the use of alcohol. This indicates that majority of the youth do not know the health implications associated with the use of alcohol. Still on the effects of alcohol use, $68 \%$ of the respondents strongly agreed that alcohol use causes low academic performance. This goes to show that there is a negative correlation between alcohol use and academic performance among the youth who are students.

\section{CONCLUSIONS}

This study has implications on nursing, nursing education, nursing administration and nursing research.

\section{Implications for Nursing Practice}

There is the need for Adolescent Friendly Services to be established on various Zongo communities which will provide counseling and nursing services for the youth on the issue of alcohol use. This is necessary because the results from the study showed that there is a high 
prevalence of alcohol use among Zongo community youth in Wa and also, most respondents were not aware of the health effects of alcohol use. As such, there is the need for health education to educate them on the negative effects associated with the use of alcohol. This would go a long way to ensure that the prevalence of alcohol use among the youth in Wa Zongo community is reduced. Also, in the process of rendering nursing care to clients who have a history of alcohol use, there is the need for nurses to offer health education on alcohol use and its effects to them. This will help to bring this problem to a minimum.

\section{Implications for Nursing Education}

Since majority of the youth do not know about the health effects of alcohol use, nurses will be in the best position to educate them on these health effects. Due to this, there is the need for the nursing curriculum to be restructured so that nurses will be given specialized training in the area of alcohol use. This will make them to make them more equipped to offer counseling services to youth in various communities on the issue of alcohol use and its health related effects.

\section{Nursing Administration}

There is the need for more resources to be allocated to deal with the issue of high prevalence of alcohol use among the youth in our various communities. This can be achieved through the setting up of adolescent-friendly services in the hospitals. Also, nurse administrators can organize in service training to help nurses to become more equipped to educate and manage our clients who have a history of alcohol use. Health education programmes need to be organized in conjunction with non-governmental organizations, religious organizations and the communities to address the problem of high prevalence of alcohol use in a culturally acceptable manner.

\section{Recommendations}

Following the findings of our research, the following recommendations have been made to control the high prevalence of alcohol use among the youth in Wa Zongo community:

Policy makers should have a more influential power over the advertisement and sale of alcohol in educational institutions. They should enforce policies to control the use of alcohol among the youth.

There should be a multidisciplinary approach to dealing with the issue of alcohol use among the youth, through the combined efforts of psychologists, psychiatrists, sociologists, educationists and law enforcement agencies.

Educationists should also include school-based alcohol prevention programmes that are imperative as they provide students with the information and skills necessary to enable them to abstain from alcohol use.

Trained counselors should also organize programmes which intend to educate on alcohol and its effects to help control use among the youth. Adolescent-friendly services should be established at vantage places such as in the communities and on university compounds to bring their services closer to people.

Alcohol anonymous groups, which are groups that bring together people who have problems related to alcohol use and addiction, should be formed on campus to help the youth who have drinking problems to share their experiences and ways by which they can deal with the problem. 
Nurses must be encouraged to give health education on alcohol use and its implications to the youth and the society.

Finally, the media can also be used to educate people on the effects of alcohol use on their health and social lives.

\section{Acknowledgements}

The researchers want to thank the editorial board of Fair East Publishers.

\section{Conflict of Interest Statement}

No conflict of interest has been declared by the authors.

\section{Funding}

The researchers have not received any support for the publication of this paper.

\section{References}

Ampofo, A. J., Amoah, S. T., \& Peprah, K. (2020). Examination of the current state of government buildings in senior high schools in Wa Municipal. International Journal of Management \& Entrepreneurship Research, 2(3), 161-193.

Ampofo, A. J. (2020). The nature of mortgage repayment plans in Ghana. Finance \& Accounting Research Journal, 2(3), 91-104.

Ampofo, A. J. (2020). Rural housing challenges in the Upper West Region of Ghana: A case study of Kulmasa. International Journal of Management \& Entrepreneurship Research, 2(4), 194-211.

Ampofo, A. J. (2020). Waste disposal management practices in selected senior high schools within the Wa Municipality of Ghana. International Journal of Management \& Entrepreneurship Research, 2(4), 273-290.

Ampofo, A. J. (2019). Reading difficulties among class six pupils of Wa Basic School Complex: Lambert Academic Publishing.

Ampofo, A. J. (2017). Community and parental influence on Senor High School (SHS) student's career choice: Lambert Academic Publishing.

Ampofo, A. J. (2017). Teachers perception towards pupils with low vision: Lambert Academic Publishing.

Atwoli P., A Mungla, M.N. Ndung'u, Kiende C. K., E.M. Ogot (2011). Prevalence of substance use among college students in Eldoret, western Kenya. BMC Psychiatry. Retrieved from www.biomedcentral.com/1471-244X/11/34 accessed on February 28th, 2012

Benzmiller, H. (2008). The Effects of Parental Attitudes And Alcohol Use on College Students Drinking. Retrieved from http://discoverarchive.vanderbilt.edu on $28^{\text {th }}$ February 2012

Castella, C. (2012). What are the Warning Signs of Alcoholism? E-How Health. Retrieved on $4^{\text {th }}$ March 2012 from E-How database

Chikere, I.C., \& Ebirem, Mayowa M.O. (2009). Prevalence and perceived health effectso alcohol and alcohol use among male undergraduates students in owerri, south-east 
Nigeria. Retrieved from www.biomedcentral.com/1471-2458/11/118 accessed on April 25th, 2012

Cresswell, J. W. (2013). Research Design. Qualitative, quantitative and mixed methods approach. London, LO: Sage Publications Inc.

Tse (2011). A comparative analysis of alcohol consumption patterns among global universities 2011, International CHRIE conference report paper 10, retrieved from http://www.scholarworks.umass.edu/refereed/ICHRIE_2011

Griffiths, S, Lau, J.T.F., Choo, J.K.W., Lee, S.S., Kan, P.Y.M.Y., \& Lee, S. (2006). Alcohol use among entrant students to a Hong Kong University. Journal of Alcohol and Alcoholism

Hingson, R., Heeren, T., Zakocks, R., Winter, M. and Wechsler, H. (2003) Age of First Intoxication, Heavy Drinking, Driving After Drinking, and Risk of Unintentional Injury Among American College Students. Journal of Studies on Alcohol, 64, 23-31

Hingson, R.W., Heeren, T., Zakocs, R.C., Kopstein, A., \& Wechsler, H. (2002). Magnitude of alcohol related mortality and morbidity among U.S College students ages 18-24 Journal of studies on Alcohol, 63, 136-144.

Hung C.C., Yen L.L., Wu, W.C. (2003) Association of Parents' Alcohol Use and Family Interaction with the Initiation of Alcohol Use by Sixth Graders; A preliminary Study in Taiwan. Retrieved on 22nd April 2012 on www.biomedcentral.com/14712458/9/9/172

Johnston, D.L., O’Malley, M.R., Schulenberg, E.J., Bacham, G.J., \& Kumar, R. (2006). How Substance Abuse Differs Among American Secondary Schools. Prevention Sceinces, 7(4), 409-420.

Johnston, H.G., Bewick, B.M., O’Connor, D., \& Schickle, D. (2011). Alcohol, Conscientiousness and Event Level Condom Use. British Journal of Health Psychology.

Laibson, D. (2001). A Cue-Theory of Consumption. The Quarterly Journal of Economics, $116(1), 81$.

Latendresse, S.J., Rose, R.J., Viken, R.J., Pulkkinen, L., Kaprio, J., \& Dick D.M. (2008). Parenting Mechanisms and Links Between Parents' and Adolescents' Alcohol Use Behaviours. Retrieved from www.sciencedaily.com on $28^{\text {th }}$ April, 2017

Marczinski, C.A., Combs, S.W., Filmore, M.T. (2007). Increased Sensitivity to the Distinguishing Effects of Alcohol in Binge Drinkers. Psychology of Addictive Behaviours, 21(3), 346-354.

Marie, S.E., \& West, R. J. (2001). Drinking Patterns and Alcohol Related Birth Defects, Alcohol Research and Health Journal, 25.

Moore, A.A., Whiteman, E.J., Ward, K.T. (2007). Risks of Combined Alcohol Medication Use in Older Adults. American Geriatric Pharmacotherapy, 5(1), 64-71

National Survey on Drug Use and Health. (2006). Underage Alcohol Use Amosng Full-Time College Students. Results from the 2005 national survey on drug use and health. Issue 31

Newburg-Birch, D., Gilvary, E., MacArdle, P., Ramesh, V., Stewart, S., Walker, J. (2009). Impact of Alcohol Consumption on Young People: A Review of Reviews London, Newcastle University 
Newman, I. (2002). Cultural aspects of drinking patterns and alcohol control in China The Global Policy Alliance. Accessed on http:// www.ias.org.uk/publications/the globe

Powell, M.L., Williams, J., \& Wechsler, W. (2002). Study Habits and the Level of Alcohol Use Among College Students. U.S.A University of Illinois, Chicago

Schulenberg, J.E., \& Maggs, J.L. (2002). Trajectories of Alcohol Use During the Transition Into Adulthood. Alcohol Research and Health, 28(4), 195-200.

Shin, S.H., Edwards, E., Heeren, T., \& Amodeo, M. (2009). Relationship Between Multiple Forms of Maltreatment by a Parent or Guardian and Adolescent Alcohol Use. American Journal on Addiction, 18(3).

Taner, S. (2005) Prevalence of Tobacco, Alcohol and Substance Use among Undergraduate Boğaziçi University Students and Exploration of Specified Risk Factors. Istanbul, Boğaziçi University.

The Centre for Disease Control Fact Sheet (2010). Underage Drinking.

The Community Anti-Drug Coalitions of America (2012). Correlation Between Rapid Rise in Unemployment and Alcohol Abuse. American Journal on Alcohol and Alcohol Addiction, 12(4).

The Institute of Alcoholism and Alcohol Abuse (2006). Alcohol Alert: Young Adult Drinking. USA, NIAAA

The National Collegiate Athletic Association (2009). A Study of Alcohol Responsibility Among College Athletes. The Sports Journal of USA Sports Academy, 12(3).

The National Institute of Alcoholism and Alcohol Abuse (2012). Alcohol and Health: Alcohol Use Disorders NIAAA Report Brochure 2012

Wechsler, H., Lee, J.E., Nelson, T.F., \& Kuo, M. (2002). Underage College Students' Drinking Behaviour, Access to Alcohol and the Influence of Deterrence Policies: Findings from the Harvard School of Public Health Alcohol Study. Journal of American College Health, 50, 223-236.

World Health Organization (2003). World Report on Violence and Health. Geneva: WHO.

Zieve, D. (2011). Alcoholism and alcohol abuse. USA University of Washington, School of Medicine 